\title{
A INTERAÇÃO FACE A FACE E O ATENDIMENTO AO CLIENTE
}

\author{
Face-to-face interaction and customer service \\ La Interacción Cara a Cara y la Atención al Cliente
}

Cynthia Maciel Duarte

Pesquisadora na PUC-Rio e Profissional de Comunicação Social

cynthia.maciel@gmail.com

Jacira Matos de Oliveira

$C M O$ - Onni Clube e Founder Saiba Planejar

Jacira.matos@saibaplanejar.com.br

\section{Resumo}

Este artigo trata do atendimento ao cliente na Loja do China, na Feira de São Cristóvão, no Rio de Janeiro - Brasil, a partir de interações sociais registradas durante pesquisa de doutorado realizada entre 2015 e 2018. O estudo apoia-se na Análise da Conversa para a microanálise dos rituais da fala-em-interação e nas ações de marketing realizadas durante o atendimento ao cliente, tendo a Etnometodologia como atitude norteadora. A observação das interações evidencia os entendimentos dos clientes sobre as mercadorias, o estabelecimento e $\mathrm{o}$ atendimento recebido, além do esforço do comerciante para lidar com esses entendimentos de modo eficiente, transformando dúvidas em vendas ou aumentando a quantidade de mercadorias adquiridas pelo cliente.

Palavras-chave: Atendimento ao cliente. Etnometodologia. Análise da Conversa.

\begin{abstract}
This article deals with customer service at Loja do China, at the São Cristóvão Fair, in Rio de Janeiro, Brazil, based on social interactions recorded during a doctoral research between 2015 and 2018. The study is based on the Conversation Analysis to perform the microanalysis of speech-in-interaction rituals and marketing actions taken during customer service, with Etnomethodology as guiding attitude. The observation of speeches and gestures in the interactions evidences the clients' understandings about the goods, the establishment and the service received, in addition to the effort of the merchant to deal with these understandings efficiently, turning doubts into sales or increasing the quantity of goods acquired by the customer.
\end{abstract}

Key words: Customer service. Ethnomethodology. Conversation Analysis.

\section{Resumen}

Este artículo trata de la atención al cliente en la Tienda de China, en la Feria de San Cristóbal, en Río de Janeiro - Brasil, a partir de interacciones sociales registradas durante la investigación de doctorado realizada entre 2015 y 2018. El estudio se apoya en el análisis de 
la conversación para realizar el microanálisis de los rituales del habla-en-interacción y en las acciones de marketing realizadas durante la atención al cliente, teniendo la Etnometodología como actitud orientadora. La observación de fallas y gestos en las interacciones evidencian los entendimientos de los clientes sobre las mercancías, el establecimiento y la atención recibida, además del esfuerzo del comerciante para lidiar con esos entendimientos de manera eficiente, transformando dudas en ventas o aumentando la cantidad de mercancías adquiridas por el cliente.

Palabras clave: Atención al cliente. Etnometodología. Análisis de la conversación.

\section{INTRODUÇÃO}

Conceitos de marketing sobre atendimento ao cliente, a Etnometodologia (EM) e a Análise da Conversa (AC) norteiam este estudo na Loja do China, um estabelecimento de pequeno porte onde são vendidos produtos alimentícios localizado na Feira de São Cristóvão, na cidade do Rio de Janeiro - Brasil. Consideramos a interação face a face para identificar como o comerciante China se relaciona com os clientes, tentando atender suas necessidades e ajustar sua interação com eles de modo a efetivar e aumentar vendas e encaminhar vendas futuras. Para isso, usamos dados de uma investigação de doutorado em Comunicação Social feita na Loja do China entre 2015 e 2018. Foram considerados fotos, anotações de campo, análises de materiais de comunicação e de ambientes online e registros em áudio e vídeo obtidos por meio de observação participante e gravações de som e imagem na Loja do China, a qual apresentamos brevemente a seguir.

\section{DESENVOLVIMENTO}

A Loja do China é um estabelecimento de venda de produtos típicos da culinária da Região Nordeste do Brasil. Está localizada na Feira de São Cristóvão, um Centro Municipal de Tradições Nordestinas na cidade do Rio de Janeiro. A Feira começou a ser formada na década de 1940, fruto de uma forte onda de imigração interna. O Rio, então capital do país, recebia investimentos em infraestrutura, o que garantia empregos na construção civil, destino de boa parte dos imigrantes. Muitos desembarcavam na cidade no Campo de São Cristóvão, uma espécie de parque em bairro de mesmo nome, nas imediações da Zona Portuária (NEMER, 2012).

Enquanto aguardavam por contratação, amigos ou parentes, muitos permaneciam no Campo de São Cristóvão (NEMER, 2012). Alguns começaram a vender ali produtos típicos de seus estados de origem, o que aos poucos fez surgir o comércio estruturado em forma de feira que hoje é conhecido como Feira de São Cristóvão. A Feira foi transferida para um pavilhão no próprio Campo em 2003, ganhando o nome oficial "Centro Luiz Gonzaga de 
Tradições Nordestinas”. Passou a funcionar de terça a domingo, com pagamento de ingresso nos fins de semana. Hoje é formada por estabelecimentos de tamanhos entre $5,6 \mathrm{~m}^{2}$ a $400 \mathrm{~m}^{2}$, como restaurantes, lojas de venda de artesanato, CDs e DVDs, lanches, bebidas, utensílios de cozinha, roupas, calçados, brinquedos e produtos típicos da culinária da Região Nordeste. Este é o caso da Loja do China, onde é possível comprar artigos como farinhas, doces, grãos e queijos.

A Feira de São Cristóvão tem um caráter descontraído evidente, dentre outros aspectos, no ambiente, decorado com bandeiras coloridas, composto por vários estabelecimentos que não possuem letreiros informando seus nomes e em que é possível encontrar em diversos locais informações sobre produtos escritas à mão. A descontração também está presente na forma com que os comerciantes abordam os clientes, usando termos como menina, patrão, colega, amigo. $\mathrm{O}$ modo de vestir de comerciantes também expressa essa característica. Muitos usam uniformes com elementos que remetem à vida rural, como chapéu de couro. Há ainda os que vestem bermuda e chinelo.

O comerciante China trabalha na Feira há 36 anos. Apesar de não ser o dono do estabelecimento, é o responsável por administrar o negócio, controlando estoques, fazendo pedidos para reposição, pagando fornecedores, organizando os produtos e limpando o espaço. Também se empenha nas vendas, sendo o negócio ancorado basicamente na presença física. $\mathrm{O}$ comerciante parece ter desenvolvido uma série de recursos para vender seus produtos tendo como base conhecimentos adquiridos de modo prático no trabalho ao longo dos anos e na vida em sociedade, já que China não domina a leitura e a escrita. São alguns desses conhecimentos e das soluções que China aciona para conquistar fregueses que compartilhamos neste trabalho, mostrando seu caráter prático e situado. Antes, esclarecemos sobre a EM e a AC.

\subsection{Etnometodologia e Análise da Conversa}

Em 1967, Harold Garfinkel publicou "Studies in Ethnomethodology", inaugurando a EM. Defendeu a pesquisa baseada na observação dos sujeitos no desenvolvimento de suas atividades cotidianas, sendo os entendimentos dos membros compreendidos por meio dessa observação os dados considerados pelo pesquisador. Rodrigues e Braga (2014) explicam que a EM é uma "atitude de encarar a realidade social", não sendo uma metodologia (p. 7). Optar pela EM significa adotar uma atitude de pesquisa praxiológica, empírica, que utiliza as pistas produzidas pelos membros em seu cotidiano para ter acesso a seus entendimentos e, assim, 
compreender lógicas que conformam determinadas configurações sociais. Nesse sentido, a conversa ajuda o etnometodólogo a entender e evidenciar como os membros dão certo sentido às situações em que se envolvem, sendo a $\mathrm{AC}$ um recurso importante na pesquisa etnometodológica.

$\mathrm{O}$ artigo "A Simplest Systematics for the Organization of Turn-Taking for Conversation", de 1974, de Sacks, Emanuel Schegloff e Gail Jefferson (1978), demonstrou que a conversa segue uma estrutura organizada socialmente. Os autores categorizaram os métodos usados pelos integrantes para organizar suas interações, sendo esses os mecanismos pelos quais as partes de uma conversa geralmente se orientam para que uma interação ocorra. Destacamos neste trabalho aqueles que serão úteis às análises feitas a seguir. Dentre eles está a explicação de que os turnos de fala contêm unidades mínimas, ao final das quais pode haver a troca de falantes. Quando isso acontece, é aberto um lugar relevante para a transição, ou seja, um ponto no qual é relevante a transição possível para um próximo orador (SACKS et al, 1974). Dentre as várias técnicas de alocação de turno empregadas em uma conversa, destacamos a "pergunta-apêndice"1, que faz uma ligação com o turno seguinte e é formada por perguntas como 'Você sabia?', 'Não concorda?', 'Né?' (SCHEGLOFF, JEFFERSON, SACKS, 2003, p. 37).

Outra contribuição importante no campo da AC é a obra "Lectures on Conversation", de 1972, um compilado de aulas de Harvey Sacks feito por seus alunos. Entre as explicações estão análises de Sacks (1972) sobre casos de storytelling, em que se contam histórias durante uma interação, tendo abordado esse recurso sob diversos aspectos. Um deles foi a adequação do que é contado aos coparticipantes, explicando que uma história não é contada ao acaso, mas de acordo com o que serve naquela interação. Em geral, a história é introduzida com uma requisição, uma espécie de aviso de que será contada uma história, o que fornece pistas ao ouvinte sobre a identificação do fim, que tem relação com o início da história. Dependendo do que foi contado, uma ação pode ser esperada, como um sorriso, no caso de uma piada, ou uma concordância, no caso de um exemplo. É importante destacar que autores de outras áreas do conhecimento também trataram de storytelling, inclusive no marketing. No entanto, neste trabalho, optamos por utilizar o storytelling de acordo com o que foi proposto por Sacks (1972), inserindo a análise na perspectiva da AC.

Sacks (1972) também tratou das piadas, que têm um tipo de estrutura diferente. "Quando você diz que vai contar uma piada, você está dizendo que será apresentada uma

\footnotetext{
${ }^{1}$ Tradução livre. No original: "tag question” (SCHEGLOFF, JEFFERSON, SACKS, 1974, p. 37).
} 
estrutura que é coerente e que eles não precisam produzir enunciados ligados a partes dela" (SACKS, 1972, p. 684). Além disso, o próximo turno ou algum outro movimento na sequência é seu fim e o fim de tudo. Se alguém conta uma piada, há uma risada em seguida. Piadas também contêm mais turnos do que aqueles que normalmente compõem uma conversa e costumam vir em rodadas, abrindo caminho para que outras sejam contadas pelos participantes.

Sendo as interações encadeamentos de falas, um dos recursos usados na AC para analisar as sequências é identificar enunciados associados entre si, os pares adjacentes. A análise de pares adjacentes permite compreender, por exemplo, o que desencadeia o quê, a quê uma expressão responde ou o que uma expressão gera como resposta. Também ajuda a identificar o desenvolvimento de turnos preferidos e não preferidos em uma interação, assunto tratado por Anita Pomerantz (1984), outra importante referência em AC. Um turno preferido seria a resposta ‘vamos sim' ao convite 'vamos almoçar hoje?'. A recusa a esse convite é um exemplo de turno não preferido, que em geral contém elementos ou turnos antes da resposta para minimizar possíveis desconfortos (Então; Bem; Tem certeza?; Agradeço, mas...). A ação não preferida costuma ser indireta, pois geralmente causa desconforto nos interagentes. Pomerantz (1984) explica ainda que a participação em atividades sociais envolve a produção de avaliações ${ }^{2}$ (assessments), que são construídas com base no conhecimento do falante a respeito do que ele avalia. Avaliações envolvem concordâncias e discordâncias, que podem ser fortes ou fracas.

$\mathrm{Na} \mathrm{AC}$, a transcrição de dados orais é feita segundo o modelo proposto no artigo de 1974 de Sacks, Schegloff e Jefferson, que não dá conta de interações registradas em vídeo, pois foi elaborado com dados sonoros. Por isso, ao modelo foram feitos acréscimos, marcados em cinza na Tabela 1 a seguir ${ }^{3}$.

Tabela 1 - Tabela de convenções de transcrição

\begin{tabular}{l|l}
\hline \multicolumn{1}{c|}{ SÍMBOLO } & \multicolumn{1}{c}{ FENÔMENO } \\
\hline$\cdot$ & Entonação descendente \\
\hline$?$ & Entonação ascendente \\
\hline, & Entonação contínua \\
\hline
\end{tabular}

\footnotetext{
2 Tradução livre. No original: assessments (POMERANTZ, 1984).

${ }^{3}$ Cientes das contribuições sobre transcrições de movimentos, neste trabalho, optamos pela apresentação de transcrições mais livres de símbolos e, portanto, mais agradáveis visualmente para leitores não familiarizados com convenções de transcrição. Foi marcado nas transcrições somente o que consideramos importante para evidenciar os dados apresentados.
} 


\begin{tabular}{|c|c|}
\hline$\sim$ fala & Entonação melódica $^{4}$ \\
\hline$: /:: /:::$ & Prolongamento do som (diferentes durações) \\
\hline$\uparrow$ & Som mais agudo (ALT +24 no teclado) \\
\hline$\downarrow$ & Som mais grave (ALT +25 no teclado) \\
\hline- & Corte abrupto \\
\hline$\underline{\text { fala }}$ & Ênfase de fala ou movimento \\
\hline FAla & Volume mais alto \\
\hline${ }^{\circ}$ fala ${ }^{\circ}$ & Volume mais baixo ou movimento curto (ALT + 167 no teclado) \\
\hline$>$ fala $<$ & Fala acelerada ou movimento rápido \\
\hline$\langle$ fala $>$ & Fala desacelerada ou movimento lento \\
\hline [ ] & Falas ou ações sobrepostas \\
\hline [ ] número & Pares de turnos ou ações sobrepostos \\
\hline (.) & Micro-pausa (igual ou inferior a dois décimos de segundo) \\
\hline$(2.5)$ & Pausa (em segundos e décimos de segundos) \\
\hline eh & Pausa cheia \\
\hline $\mathrm{mm}$ & Sinal de retorno ou de resposta do ouvinte \\
\hline .h / .hh / .hhh & Inspiração (diferentes durações) \\
\hline $\mathrm{h} / \mathrm{hh} / \mathrm{hhh}$ & Expiração (diferentes durações) \\
\hline th & Estalar de língua \\
\hline $\begin{array}{l}\ldots= \\
=\ldots\end{array}$ & Turnos contíguos (ausência de pausa interturnos) \\
\hline$=$ & Ausência de uma micropausa intraturno (entre duas palavras) \\
\hline() & Segmento inaudível não transcrito \\
\hline (fala) & Segmento pouco audível de transcrição duvidosa \\
\hline (fala/fama) & Transcrições alternativas de um segmento pouco audível \\
\hline$(($ escreve $))$ & Descrição de uma atividade não verbal \\
\hline$\$^{5}$ & Fala misturada com riso \\
\hline$\theta$ & Movimento de fala, mas sem emissão de som \\
\hline
\end{tabular}

Fonte: Tabela feita com base em Sacks, Schegloff e Jefferson (1974); Jefferson (2004); Rodrigues (2005) e Duarte (2019), estas escritas em cor mais clara.

Essas considerações sobre EM e AC são importantes para a compreensão das análises feitas a seguir. Antes, apresentamos alguns conceitos de marketing que ajudam a explicar aspectos encontrados nos dados.

\subsubsection{O marketing e o atendimento ao cliente}

Em mercados altamente disputados, com produtos de qualidade semelhante, é preciso que as empresas direcionem o foco para a satisfação do cliente, obtida tanto pela aquisição de um produto que atenda as suas necessidades quanto pelo excelente atendimento, sendo o último o que a diferenciará em relação à sua concorrente que oferece os mesmos produtos.

\footnotetext{
${ }^{4} \mathrm{O}$ til se refere a um modo de falar cuja entonação expressa uma atitude de simpatia em relação ao interlocutor, sendo usado neste trabalho no início e no fim desse tipo de expressão.

${ }^{5} \mathrm{O}$ uso deste símbolo foi inspirado na apresentação feita por Rony Ron-Rén no II Encontro Nacional da Análise da Conversa Etnometodológica (ENACE).
} 
Kotler e Armstrong (2003) afirmam que as empresas devem estar voltadas para o cliente de modo a entregá-lo valor superior, objetivando assim conquistá-lo dos concorrentes e mantê-lo.

As ações desenvolvidas por uma empresa, a partir de uma estratégia de marketing, possibilitam identificar as necessidades e desejos de um potencial cliente e, portanto, entregar valor para satisfazer as necessidades de um mercado-alvo com lucro (KOTLER, 2000). Um dos principais objetivos do marketing é entregar valor superior aos clientes em relação às ofertas concorrentes (WEBSTER, 1992). De acordo com Freemantle (1994), esse valor pode estar no atendimento ao cliente, que desempenha um papel de teste final. Isso porque, a empresa pode se esforçar ao máximo para oferecer um bom produto e com preço competitivo, mas, se não completar o processo com um atendimento excelente, pode perder a venda ou até sair do mercado. O tratamento dado ao cliente é extremamente importante para o sucesso do negócio.

Kotler, Hayes e Bloom (2004) destacam que "todo mundo gosta de ser tratado como alguém importante. A capacidade de fazer cada cliente se sentir especial e importante constitui o ponto crucial para estabelecer empatia” (p. 58). Ser cortês com todos os clientes é um desafio. Para Santos (1995), é preciso encantá-los sempre. "O cliente que não é tratado como objeto, certamente voltará a sua empresa para fazer novas compras e garantirá não só a continuidade, mas também o sucesso de seu negócio. Procure encantá-lo o tempo todo" (p. 31). Bezerra (2013) destaca que:

Satisfazer um consumidor não é fácil. Acredite! O que é satisfatório para uma pessoa pode ser insatisfatório para outra. Clientes são indivíduos que possuem características, opiniões e gostos diversos (...). Nunca vamos conseguir satisfazer $100 \%$ dos clientes, mas é necessário fazermos o máximo de esforço para conseguimos alcançar o mínimo de satisfação esperada por eles (p. 12).

Nesse contexto, é preciso observar que o modo como se fala e demonstra o seu interior através de expressão corporal, facial, tom de voz e até olhar pode desempenhar um papel mais importante na interação do que o que se disse (TSCHOHL, 1996). Desafio que, durante o atendimento ao cliente, leva à necessidade de se recorrer a artifícios como o storytelling lúdico, um facilitador no desempenho da interação. Bergson (1960) explica que ao contar uma história empregando efeito cômico em elementos que possuem sentido próprio obtém-se o riso e, portanto, a empatia daquele que ouve a piada. $\mathrm{O}$ autor afirma que o riso pressupõe entendimento prévio para criar cumplicidade com os outros que riem, estando o riso no âmbito da inteligência, se opondo à emoção, sendo o riso sempre o riso de um grupo. 
Além das histórias lúdicas, a degustação de produtos é um dos recursos de venda, integrando as ações de merchandising realizadas em estabelecimentos comerciais, principalmente em lojas de varejo, tendo como objetivo expor e apresentar os produtos de maneira adequada para criar impulsos de compra na mente dos consumidores (SILVA, 1990). Na maioria das vezes, é uma estratégia de baixo custo e de alto retorno para os comerciantes. Oferecer uma amostra do produto ao cliente para que este conheça as vantagens do mesmo, aliado a um bom atendimento, incentiva o consumidor a comprar o produto e a retornar mais vezes à loja (BLESSA, 2005).

A Loja do China está em local onde a concorrência é acirrada e em que para se destacar é preciso não apenas oferecer bons produtos, mas trabalhar na construção de clientes, de modo que a solução passa por entregar valor e satisfação melhor do que os concorrentes (KOTLER; ARMSTRONG, 2003). China não teve acesso às teorias de marketing apresentadas aqui. No entanto, os dados da pesquisa mostram que em suas ações estão incluídos muitos conhecimentos envolvidos nas estratégias de satisfação do cliente. Os recursos usados por ele parecem ter como base a experiência adquirida durante anos exercendo o atendimento na Loja, fato que reforça a importância da microanálise dos rituais da fala-em-interação para compreender as estratégias desempenhadas, o que apresentamos nos casos descritos a seguir.

\subsubsection{Interação entre fregueses e comerciante na Loja do China}

Os conhecimentos e as soluções que China aciona para atender fregueses são reunidos em quatro categorias de análise neste trabalho: relações horizontalizadas, caráter cordial da interação, storytelling lúdico e degustação de produtos. Essas categorias não têm fronteiras rígidas, sendo possível perceber características que se repetem. No entanto, pareceu-nos pertinente fazer essa categorização a título de melhor compreensão dos dados.

\section{Relações horizontalizadas}

Conforme mencionado, a Feira de São Cristóvão é um ambiente descontraído. A Loja do China reproduz essa característica. O atendimento aos clientes é marcado por piadas, afirmações com base em conhecimentos de senso comum que suscitam risadas e orientações para o uso de produtos vendidos na Loja. É essa característica descontraída no trato com os clientes, que parece ser um esforço de China para estabelecer uma aproximação maior com as 
pessoas, que nos faz categorizar muitas relações estabelecidas entre China e seus fregueses como horizontalizadas.

Em um dos casos, China (Ch) reverte em venda uma situação de visível dúvida de duas freguesas $\left(\mathrm{V}\right.$ e $\mathrm{X}^{6}$ ) sobre comprar a goma da mandioca ao ensiná-las com detalhes a preparar a tapioca ${ }^{7}$ (gravação em 30/04/2017, Loja do China). Nesse exemplo, as contribuições de Kotler, Hayes e Bloom (2004) sobre fazer o cliente se sentir especial parecem ajudar a compreender a importância da atenção focada no freguês.

Parada no balcão com um saco de goma, V pergunta se o produto está peneirado. Tendo recebido resposta afirmativa, $\mathrm{V}$ pergunta se a goma estava boa. China responde que sim, acrescentando que aquela era "da mandioca mesmo" e que V poderia "levar garantido". V pergunta se era "só botar na frigideira sem nada". Interessante perceber pela resposta de China sua compreensão de que V usaria a goma para fazer tapioca mesmo sem que ela tivesse dito isso, apenas por associar o fato de colocar a goma na frigideira a uma etapa do preparo desse alimento. Isso porque, a goma também pode ser usada para fazer pão de queijo, crepe, dentre outras iguarias.

China responde que sim, adicionando que ela poderia colocar sal. V confirma com China que poderia colocar sal ou açúcar. Logo em seguida, X pergunta o valor. China informa que a goma custava $\mathrm{R} \$ 7\left(€ 1,57^{8}\right)$. V e X ficam em silêncio olhando para o pacote da goma nas mãos de V. China então produz uma avaliação (POMERANTZ, 1984) da goma, afirmando que aquela goma era "da boa mesmo", "especial mesmo" e que muitos estabelecimentos na Feira vendiam polvilho molhado, afirmando que ele não, pois vendia "a goma da mandioca mesmo".

$\mathrm{V}$ e $\mathrm{X}$ voltam para perto da prateleira das gomas. V passa a mão em alguns sacos de goma e troca o que segurava por outro, voltando para o balcão. V se dirige ao comerciante, que acabava de atender a outros fregueses.

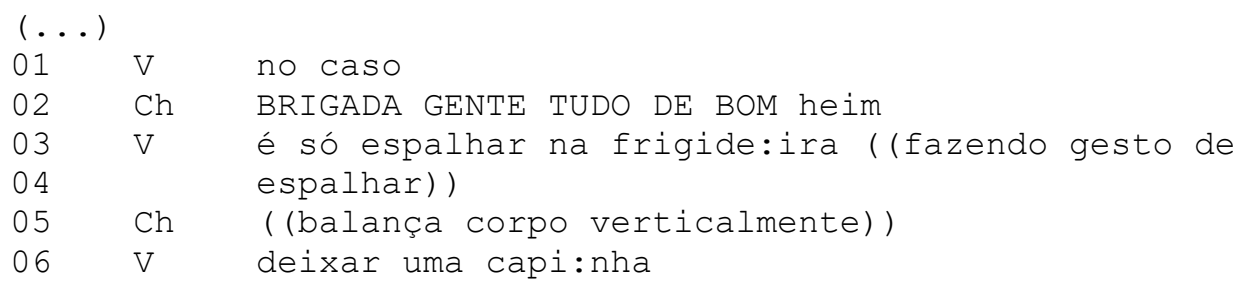

\footnotetext{
${ }^{6}$ As letras usadas para identificar os participantes neste trabalho são as mesmas usadas na tese que deu origem a este artigo.

${ }^{7}$ Goma de mandioca é o amido hidratado da mandioca, um dos nomes que a espécie de planta Manihot esculenta recebe no Brasil. Mais informações em https://www.embrapa.br/mandioca-e-fruticultura/cultivos/mandioca. A tapioca é uma espécie de panqueca feita com a goma da mandioca.

${ }^{8}$ Neste trabalho foi usada a cotação de R \$ 4,44 para o Euro, valor praticado em 24/04/2019.
} 


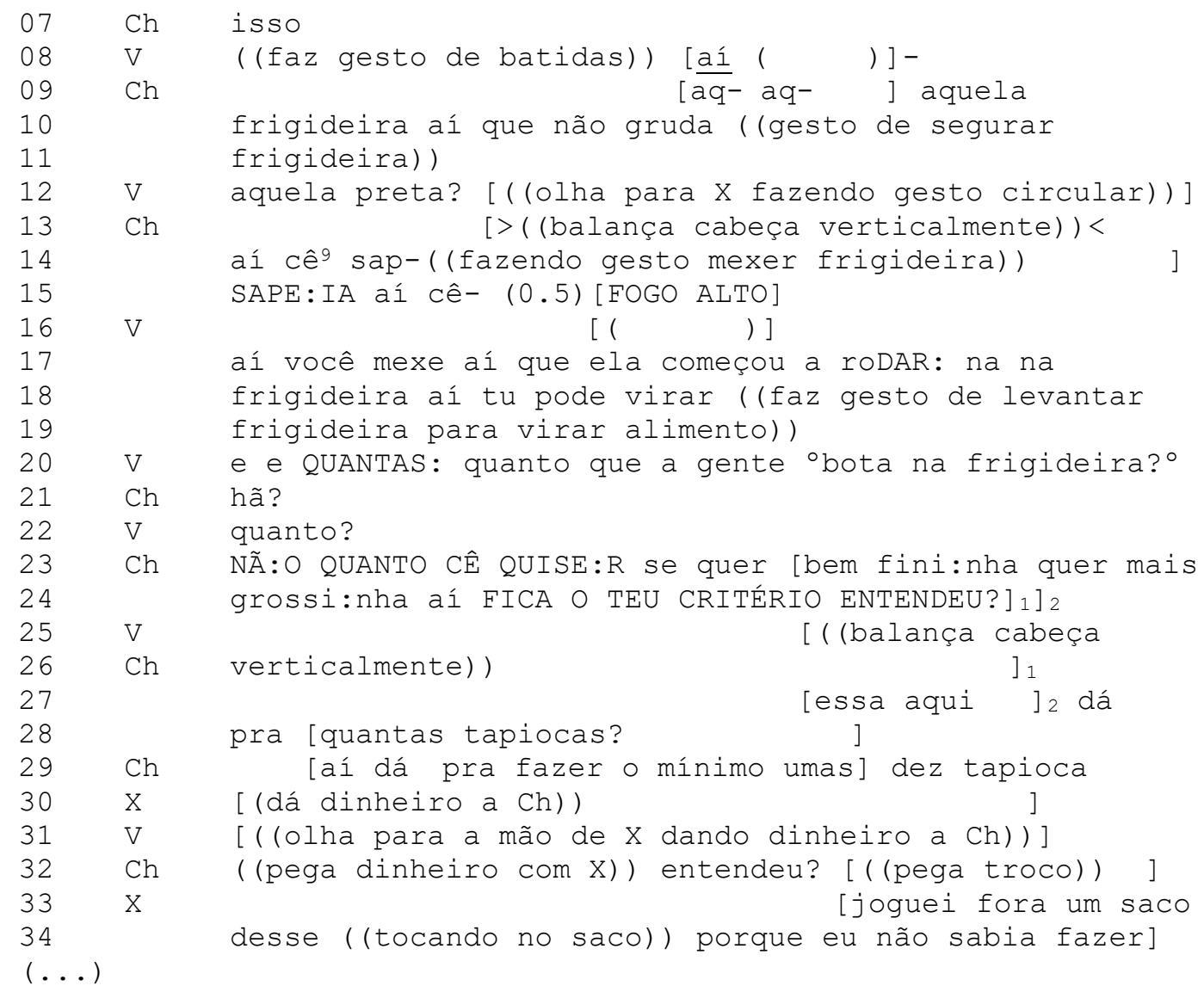

Mesmo depois do pagamento, China continua explicando sobre o preparo, agora para $\mathrm{X}$, acrescentando o local mais apropriado da geladeira para guardar a goma (na beirada da geladeira, na parte mais alta, que gela mais $)^{10}$, e afirmando que $X$ não tinha conseguido preparar a tapioca anteriormente porque teria usado polvilho molhado.

Percebe-se que V retoma a conversa com China a partir do assunto sobre o uso da goma para o preparo da tapioca, iniciando a partir desse ponto uma troca de turnos colaborativa entre ambos, em que $\mathrm{V}$ começa descrevendo as etapas do modo de preparo (no caso, é só espalhar na frigideira, deixar uma capinha), com as quais China, a cada lugar relevante de transição de falante (SACKS et al, 1974), manifesta concordância por meio do uso de continuadores (balança corpo verticalmente, isso), incentivando $\mathrm{V}$ a prosseguir, e também faz complementos. Assim, se inicialmente é $\mathrm{V}$ quem descreve as etapas da produção, durante a explicação é China quem assume o piso interacional, tendo reivindicado o mesmo pelo acréscimo de uma informação (aquela frigideira aí que não

\footnotetext{
${ }^{9} \mathrm{C} \hat{\mathrm{e}}=$ você

${ }^{10}$ Ao reproduzir a conversa no texto, entre parênteses, ou seja, fora da transcrição, usamos os sinais de pontuação com o sentido em que os mesmos são empregados nos textos correntes, sem os significados que assumem na transcrição segundo a Análise da Conversa.
} 
gruda). A partir daí, China assume a narração do modo de preparo da tapioca (aí cê sapeia...), após o que $\mathrm{V}$ faz perguntas (quanto que a gente bota na frigideira? Dá pra quantas tapiocas?) e China responde (...o quanto cê quiser..., aí dá pra fazer o mínimo umas dez tapioca).

Percebe- se nesse exemplo o sentido das palavras de Freemantle (1994) sobre o atendimento excelente ao cliente. Vê-se que o comerciante explicou toda a etapa de produção da tapioca, tendo ainda repetido partes do processo. Mesmo afirmando não ter conseguido preparar a tapioca em ocasiões anteriores, $\mathrm{X}$ concorda em comprar o produto após as explicações de China.

\section{Caráter cordial da interação}

Mesmo diante de situações em que o freguês manifesta desconfiança dos produtos, a relação tende a se manter com um caráter cordial, o que pode ser consequência do modo como China se coloca à disposição para os fregueses. Parece ser o caso de que trata Bezerra (2013) ao destacar a importância do esforço na satisfação do cliente, o que não é tarefa fácil.

Foi o que aconteceu na conversa com $\mathrm{R}$, em que China se esforça para satisfazer a cliente e efetuar a venda (gravação em 30/04/2017, Loja do China). R pergunta sobre a massa puba ${ }^{11}$. Durante a conversa, a freguesa manifesta a desconfiança de que o produto não esteja bom, o que China contesta.

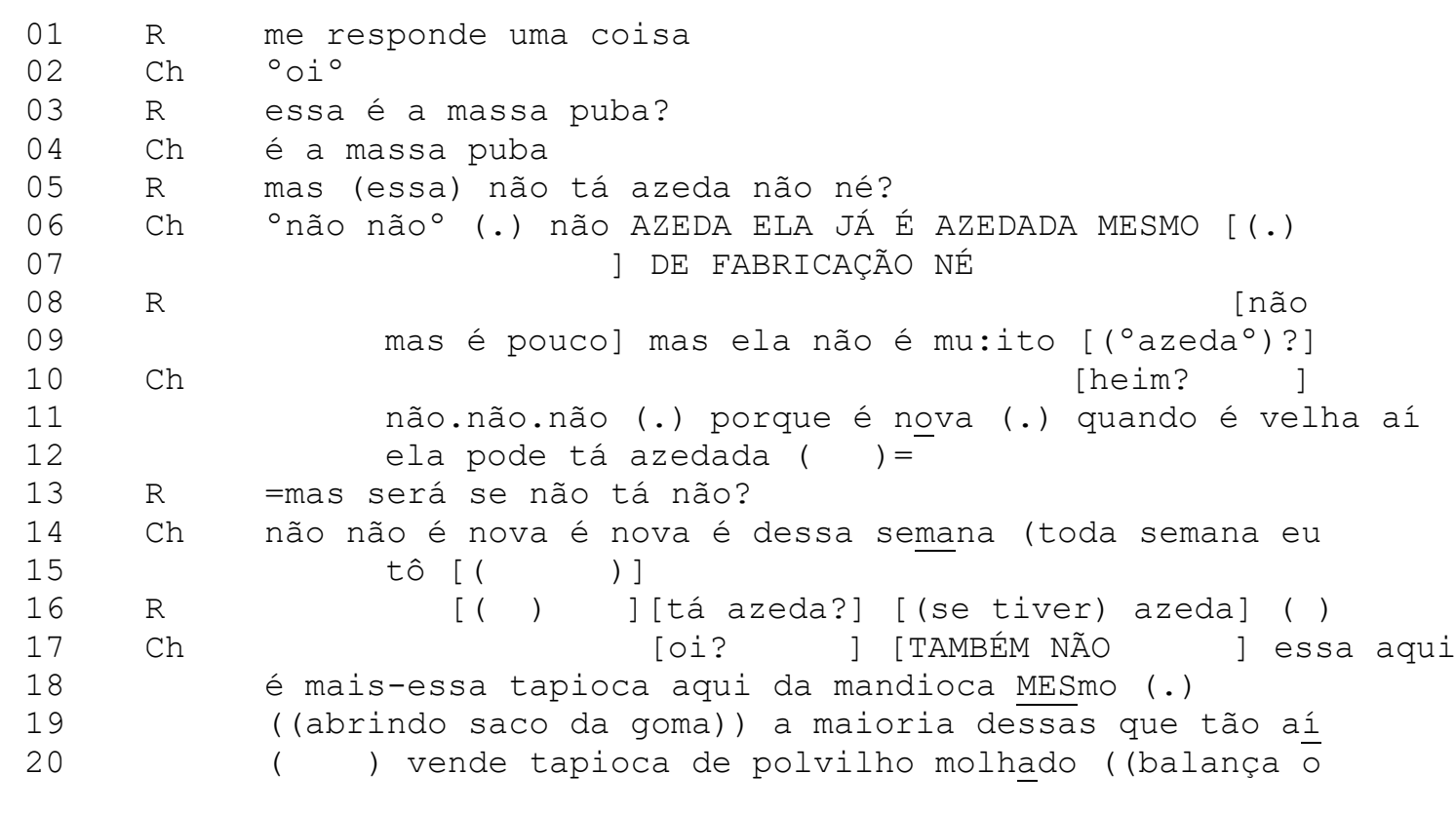

${ }^{11}$ Trata-se de um tipo de massa feita da mandioca e usada no preparo de bolos, entre outros alimentos. 


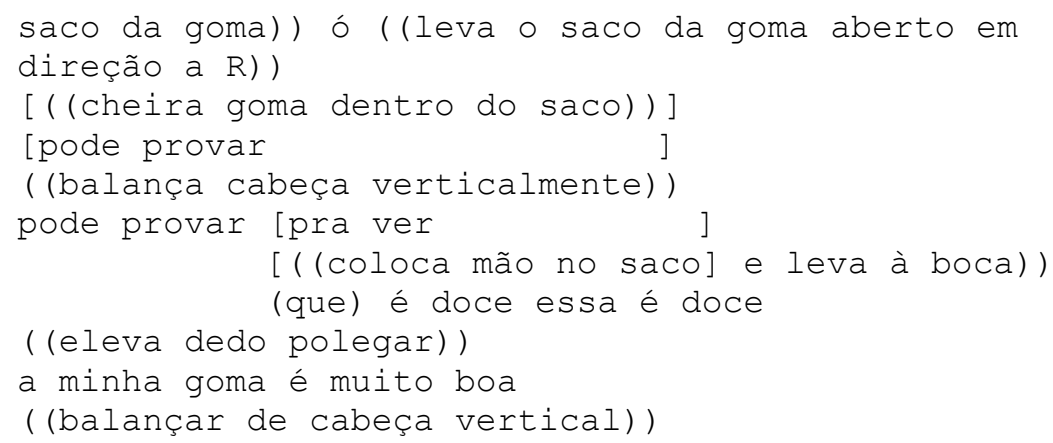

É possível ver nesta interação um esforço de China em garantir a $\mathrm{R}$ que o produto estava bom e que por isso ela poderia comprar. Logo que R pergunta sobre a possibilidade de a massa estar azeda (mas essa não tá azeda não, né?), China menciona o fato de o produto ter como característica ser azedo. Assim, ele se empenha em inserir outro entendimento para o termo (não, azeda ela já é azedada mesmo, de fabricação). Ao fazer isso, China parece fazer um reparo na pergunta de $\mathrm{R}$, se esforçando em inserir o termo em uma categoria de uma coleção 'modo de preparo' ou 'característica do produto' em lugar de uma categoria de uma coleção 'estado de conservação do produto'. R então faz um reparo na afirmação de China (não, mas é pouco) para mostrar que tinha conhecimento da característica do produto ao qual o comerciante se referiu, mas que de fato queria saber sobre o estado de conservação do mesmo. Para isso, $\mathrm{R}$ insere a especificação do tipo de azedo ao qual ela estava se referindo (mas ela não é muito azeda?). Assim, China e R se envolvem em um trabalho interacional de estabelecimento de "acordo compartilhado" sobre o que entendem a respeito da massa puba (GARFINKEL, 2009, p. 128). $R$ interessada em saber se o produto não estava mais azedo do que o normal, e China empenhado em explicar que ser azedo fazia parte do produto.

Interessante observar que nessa troca de turnos, $\mathrm{R}$ constrói seus turnos de modo a minimizar o desconforto da desconfiança. $\mathrm{R}$ afirma que a massa não está azeda e solicita a concordância do comerciante a respeito dessa avaliação por meio da inserção de uma pergunta apêndice (mas essa não tá azeda não, né?) (SCHEGLOFF, JEFFERSON, SACKS, 1974). Ao fazer isso, $\mathrm{R}$ cria condições para que China produza em seu turno uma concordância com a afirmação que ela fez (não, não), seguindo assim pelo caminho preferido, que é concordar que a massa não está muito azeda (POMERANTZ, 1984). Afinal, estando a massa muito azeda, ela não deveria estar ali exposta para ser comprada.

$\mathrm{R}$ pergunta novamente se a massa é muito azeda, usando estrutura similar (mas ela não é muito azeda?). Apesar de poder ser entendida como uma discordância em relação ao 
que China havia dito, por ser feita em forma de pergunta, e uma pergunta com estrutura similar à feita anteriormente, de modo que a negação na resposta seja o caminho preferido (mas ela não é muito azeda?), entende-se que se trata de uma discordância fraca. Isso cria condições para que o comerciante continue empenhado em argumentar a favor de a massa puba estar em boas condições para consumo. Assim, China faz uso de outro recurso para convencer R: acrescenta uma explicação que sustenta sua afirmação de que a massa não está muito azeda (porque é nova). $\mathrm{R}$ não se dá por satisfeita e produz uma nova pergunta a respeito de a massa estar azeda (mas será se não tá não?). O recurso usado por China nesse momento é repetir a informação já dada com mais ênfase (é nova, é nova) e inserir um novo dado, que é a especificação do que ele afirma ser nova: dessa semana.

Até esse momento, China faz uso da fala para tentar garantir a $\mathrm{R}$ que o produto estava bom para consumo. A partir deste ponto, quando $\mathrm{R}$ se refere a outro produto, a goma da mandioca, China faz uso de outros recursos. O comerciante insere uma avaliação (POMERANTZ, 1984) que não mais se refere à coleção 'estado de conservação', mas sim à coleção 'matéria-prima do produto', informando se tratar de uma goma feita "da mandioca mesmo". Devido às perguntas feitas pela freguesa, percebe-se que o aspecto, tanto da massa quanto da goma, não estava sendo suficiente para que $\mathrm{R}$ sentisse segurança em comprar os produtos. Apesar de não oferecer uma prova da massa puba, em relação à goma da mandioca, além de acionar a composição do produto como atributo de qualidade, o comerciante adota o recurso usado em relação ao queijo e oferece uma prova da goma, ocorrência única nos dados. Nesse ponto, é importante lembrar a contribuição de Tschohl (1996), que enfatiza a importância de se priorizar uma atitude cortês. A interação continua, com R comprando outro produto, além da massa e da goma, e levando um cartão da Loja. O sucesso da venda nessa interação parece ter relação com o que foi tratado por Santos (1995) sobre o cliente não ser tratado como objeto.

\section{Storytelling lúdico}

Outro recurso usado por China é contar histórias, o storytelling (SACKS, 1972). Conforme já mencionado, cientes de que autores de outros campos do conhecimento, inclusive do marketing, trataram deste tema, neste trabalho optamos por utilizar o conceito de storytelling conforme proposto por Sacks (1972), portanto, segundo a Análise da Conversa (AC). Um dos modos como China utiliza esse recurso é de forma lúdica. Em um dos registros, um grupo de três pessoas $(\mathrm{Gr} 2)$ olha produtos em frente ao freezer frontal da Loja, 
que fica no limite entre o estabelecimento e a parte externa, enquanto China fala com outras pessoas dentro da Loja (Gr1). Um dos fregueses do grupo Gr2 pergunta o valor do queijo coalho. Outra integrante deste grupo (A1) pede um cartão da Loja. Ao entregar, China faz uma brincadeira.

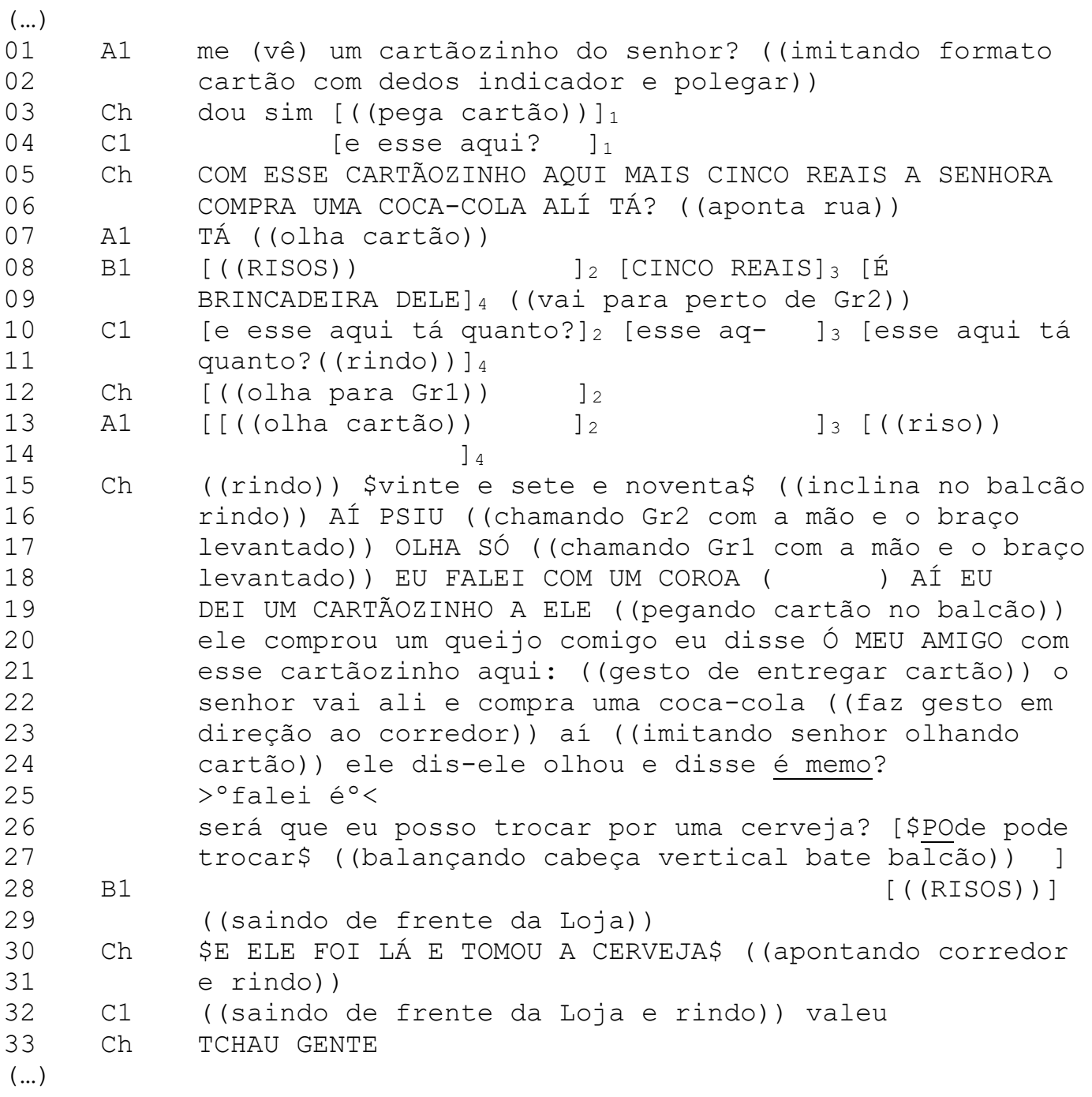

Ao entregar o cartão e aparentemente oferecer um benefício (com esse cartãozinho mais cinco reais a senhora compra uma Coca-Cola ali, tá?), China obtém a atenção de A1, que olha o cartão enquanto o comerciante fala. Por usar uma pergunta apêndice (SCHEGLOFF, JEFFERSON, SACKS, 1974), China conta com a relevância de uma resposta e a obtém de A1 (tá), que, pela ausência do riso, demonstra que não havia identificado a brincadeira. Esta, entre o Gr2, foi identificada primeiramente por B1, que ri e diz se tratar de uma brincadeira do comerciante (isso porque, com $\mathrm{R} \$ 5$ - cerca de $€ 1,10$ - se compraria um refrigerante mesmo não apresentando o cartão). 
Em seguida, A1 e C1 começam a rir. As demais pessoas que estavam na Loja também acham graça. Nesse ponto, é pertinente lembrar Henri Bergson (1960), segundo o qual o riso está no âmbito da inteligência e é sempre o riso de um grupo. China também ri com o grupo e antes que as pessoas deixem seu estabelecimento reuni-os em torno de uma história.

A situação envolve contar uma história e também fazer uma brincadeira, com China iniciando uma história na sequência de uma primeira. Ele anuncia isso ao chamar a atenção dos dois grupos que estavam em sua Loja, demonstrando que não queria apenas falar, mas queria falar para todos (aí psiu, chamando Gr2 com a mão e o braço levantado; olha só, chamando Gr1 com a mão e o braço levantado), configurando uma busca pelo piso interacional (SACKS, 1972).

China conta a situação em que fez a mesma piada, mas foi levado a sério pelo freguês. O não reconhecimento da brincadeira pelo freguês, ou seja, a não ocorrência de um "acordo compartilhado" (GARFINKEL, 2009, p. 128) a respeito de se tratar de uma piada, foi evidenciado pela ausência de riso, pela pergunta do freguês sobre ser possível trocar o refrigerante por uma cerveja e por sua ida ao estabelecimento para retirar o benefício. O relato desse acontecimento fez daquela situação uma piada para China e para o grupo que ouvia o caso naquele momento.

Semelhante ao que Sacks (1972) propôs, China não precisou informar aos grupos Gr1 e Gr2 que a história contada se tratava de uma piada. Os grupos demonstram esse entendimento ao não terem iniciativas de tomada de turno enquanto a mesma não acaba e ao rirem no fim, mesmo tendo faltado o elemento que caracterizava a história como uma piada: o fato de o "coroa" ter que levar os cinco reais junto com o cartão (ó, meu amigo, com esse cartãozinho aqui o senhor vai ali e compra uma Coca-Cola). Apesar disso, os presentes ouviram a brincadeira como tal, devido àquela feita anteriormente.

\section{Degustação de produtos}

Uma prática comum de China é a oferta gratuita de um pedaço de queijo para ser experimentado antes da conclusão da compra, a prova ou "provinha", como China costuma dizer. Assim, China explora com maestria a estratégia de merchandising (SILVA, 1990; BLESSA, 2005). Frequentemente, quando o freguês vai comprar queijo, antes de perguntar a quantidade, o comerciante corta um pequeno pedaço, espeta na ponta da faca e o oferece ao freguês. 
Em geral, os fregueses reconhecem essa oferta como uma prática comum. É o que mostra a gravação envolvendo um homem (P) e uma mulher (Q) (gravação em 10/12/2016, Loja do China).

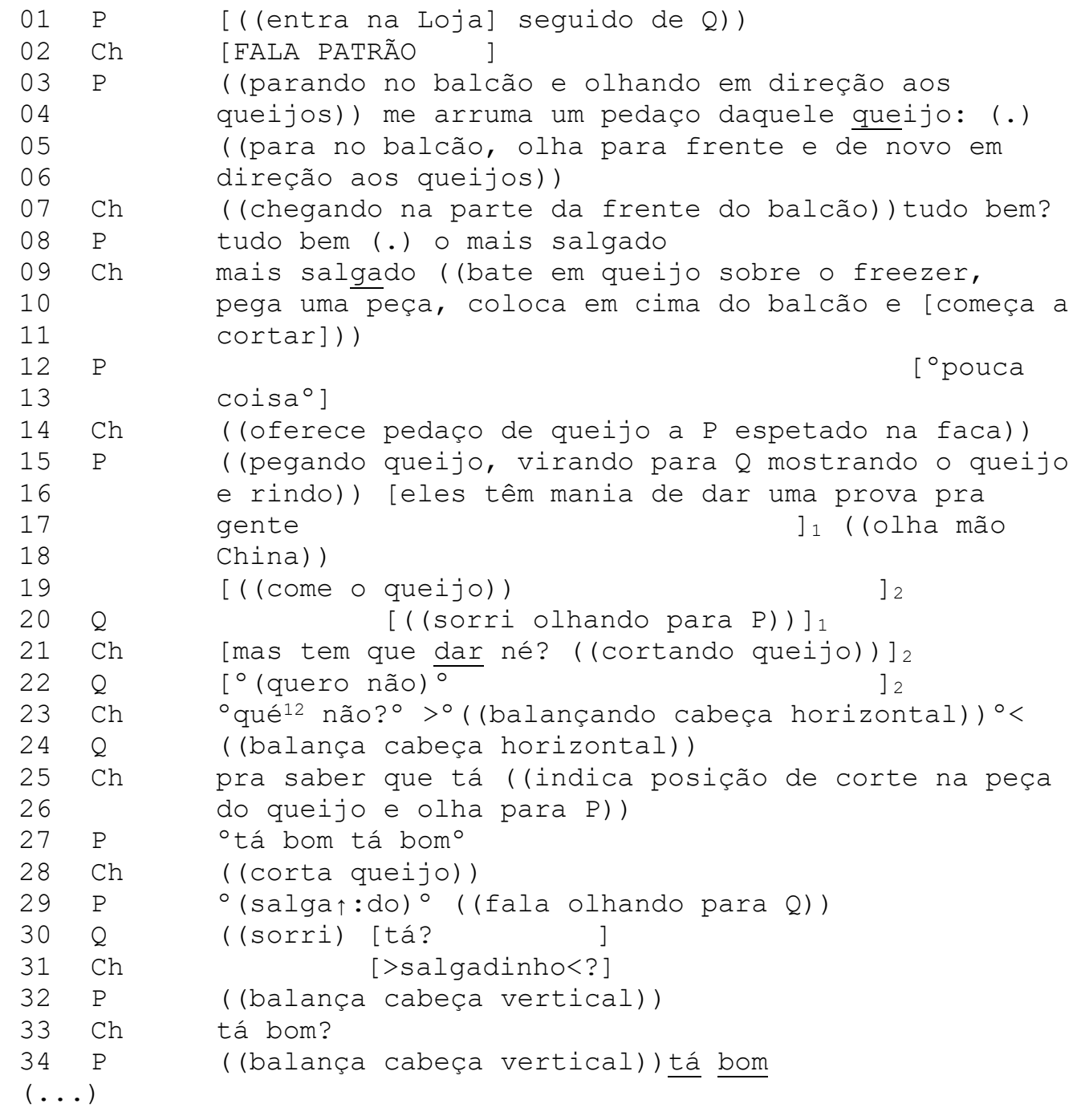

Essa interação é especialmente interessante devido à formulação que freguês e comerciante fazem a respeito da oferta da prova (GARFINKEL; SACKS, 1970). P afirma que aquela é uma prática naquele ambiente (eles têm mania de dar uma prova pra gente). China, apesar de não concluir o turno (pra saber que tá), evidencia que o motivo da oferta da prova é oferecer ao freguês condições de fazer uma avaliação do produto antes de comprar (POMERANTZ, 1984). O interesse pela expressão dessa avaliação é evidenciado quando o comerciante pergunta sobre o produto provado (tá bom?). Portanto, é possível afirmar que o trabalho interacional de venda do queijo por China inclui essa avaliação pelo freguês.

${ }^{12}$ Qué = quer 
Ao fazer isso, China conta com o caráter de uma avaliação de não apenas ser constituída em uma interação, mas também de constituí-la. É possível perceber que ao ouvir o freguês afirmar que o queijo estava salgado, China usa o adjetivo no diminutivo (salgadinho), em um esforço de enfatizar a característica daquele produto como positiva. Ao oferecer um pedaço, ouvir a avaliação do produto e incentivar que a avaliação do mesmo seja positiva, a prova do queijo contribui para a existência de mais conversa entre freguês e comerciante e para o estabelecimento de uma interação em que a cordialidade ganha evidência. Esse 'falar mais' parece ser um modo de proceder bastante usado por China nas interações com os fregueses.

\section{CONSIDERAÇÕES}

Os casos apresentados mostram que a interação face a face fornece informações para que o comerciante China acione os recursos de que precisa para eliminar dúvidas e fazer com que os clientes avancem para a compra. Assim, o esforço de China em conquistar e manter clientes tem como importante base seu empenho em desenvolver conversas com os fregueses. Os dados apresentados evidenciam como essas conversas ajudam na compreensão dos entendimentos uns dos outros e parecem contribuir para a conquista e a manutenção da clientela. China parece se empenhar, por exemplo, em manter relações horizontalizadas, ou seja, com uma aproximação maior com os fregueses, como no caso em que ensina com detalhes a preparar produtos com a mercadoria desejada. A cordialidade também parece ser aspecto importante, mesmo quando um produto de China é questionado, como aconteceu com a cliente R. Durante a conversa, o comerciante se esforçou em sanar suas dúvidas, concretizando a venda. Outro recurso usado pelo comerciante apresentado neste trabalho foi o storytelling lúdico, como no caso da história sobre o cartão de visitas. Também mostramos que China costuma oferecer uma prova de queijo ao cliente, que parece contribuir para que o consumidor compre e retorne à Loja em outros momentos.

Os exemplos evidenciam a importância de analisar as configurações sociais a partir dos ambientes e das interações entre as pessoas, de forma naturalista, localmente situada. Em âmbito mais amplo, mostram que as pessoas em seu cotidiano adotam comportamentos metódicos e ordenados, inclusive durante as compras, e que a EM, combinada à AC, oferece acesso a esses métodos e ordens. Assim, defendemos que a EM e a AC podem contribuir não apenas para as investigações nas Ciências Sociais e na Comunicação Social, mas podem ser também importantes formas de se compreender em profundidade maneiras de se estabelecer 
melhores relações com clientes e, consequentemente, ajudar no desenvolvimento de empreendimentos comerciais.

\section{REFERÊNCIAS}

BERGSON, Henri. O riso: ensaio sobre o significado do cômico. Lisboa: Guimarães Editores, 1960.

BEZERRA, Igor Salume. Qualidade do ponto de vista do cliente. São Paulo: Biblioteca 24horas, 2013.

BLESSA, Regina. Merchandising no ponto-de-venda. 3 ed. São Paulo: Atlas S.A, 2005.

DUARTE, Cynthia Maciel. Comunicação e etnometodologia na Feira de São Cristóvão: interação social e comércio na Loja do China. 2019. 439 f. Tese (Programa de Pós-graduação em Comunicação Social) - Dep. Comunicação Social, PUC-RJ. Rio de Janeiro, 2019.

FREEMANTLE, David. Incrível Atendimento ao Cliente. São Paulo: Makron Books, 1994.

GARFINKEL, Harold. Studies in Ethnomethodology. New Jersey: Prentice-Hall Inc, 1967.

GARFINKEL, Harold; SACKS, Harvey. On Formal Structures of Practical Actions. In: MCKINNEY, John C.; TIRYAKIAN, Edward (Eds.). Theoretical Sociology: Perspectives and Development. Appleton-Century-Crofts: New York, 1970, p. 338-366.

JEFFERSON, Gail. Glossary of transcript symbols with an introduction. In: LERNER, Gene. Conversation Analysis: studies from the first generation. Amsterdã, Filadélfia: John Benjamins Publishing Company, 2004.

KOTLER, Philip. Administração de Marketing. 12. ed. São Paulo: Prentice Hall, 2000.

KOTLER, Philip; ARMSTRONG, Gary. Princípios de Marketing. 9. ed. São Paulo: Prentice Hall, 2003.

KOTLER, Philip; HAYES, Tom; BLOOM, Paul. Marketing de Serviços Profissionais. 2. ed. São Paulo: Manole, 2004.

NEMER, Sylvia Regina Bastos. Feira de São Cristóvão: contando histórias, tecendo memórias. 2012. 255 f. Tese (Programa de Pós-graduação em História Social da Cultura) - Dep. História do Centro de Ciências Sociais, PUC-RJ. Rio de Janeiro, 2012.

POMERANTZ, Anita. Agreeing and disagreeing with assessments: some features of preferred/dispreferred turn shapes. In: ATKINSON, J. Maxwell; HERITAGE, John. Structures of Social Action. Cambridge: Cambridge University Press, 1984. p. 57-101.

RODRIGUES, Adriano Duarte. A partitura invisível: para uma abordagem interactiva da linguagem. $2^{\mathrm{a}}$ Ed., Lisboa: Colibri, 2005 [2001].

RODRIGUES, Adriano Duarte; BRAGA, Adriana. Análises do discurso e abordagem etnometodológica do discurso. In: Matrizes. Vol. 8, N 2, jul./dez., 2014. Disponível em:

http://www.periodicos.usp.br/matrizes/article/viewFile/90450/93225. Acesso em: 18 fev. 2019. 
SACKS, Harvey. Lectures on Conversation. Oxford: Blackwell, 1992 [1972].

SACKS, Harvey; SCHEGLOFF, Emanuel; JEFFERSON, Gail. A Simplest Systematics for the Organization of Turn Taking for Conversation. Language, Vol. 50, No 4, 1974, p. 696-735. Tradução Maria Clara Castellões de Oliveira e Paulo Cortes Gago (Coords.). In: Veredas, Juiz de Fora, Vol.7, $\mathrm{N}^{\mathrm{o}} 1$ e $\mathrm{N}^{\mathrm{o}} 2$, jan./dez. 2003, p. 9-73. Disponível em:

http://www.ufjf.br/revistaveredas/files/2009/12/artigo14.pdf. Acesso em: 28 mar. 2018.

A Simplest Systematics for the Organization of Turn-Taking for Conversation. In: Studies in organization of conversational interaction. Nova York: Academic Press, 1978 [1974]. Disponível em http://www.liso.ucsb.edu/liso_archives/Jefferson/systematics_Schenkein.pdf. Acesso em: 28 mar. 2018.

SANTOS, J. J. Encantar o cliente dá lucro: revolucione sua empresa e ame os seus clientes: fatores primordiais de diferenciação dos concorrentes. Rio de Janeiro: Campus, 1995.

SILVA, Caroline Rodrigues; ANDRADE, Daniela Negraes P.; OSTERMANN, Ana Cristina. Análise da Conversa: uma breve introdução. ReVEL, Vol. 7, N 13, 2009. Disponível em:

http://www.revel.inf.br/files/artigos/revel_13_analise_da_conversa.pdf. Acesso em: 28 mar. 2018.

SILVA, Joaquim Caldeira da. Merchandising no varejo de bens de consumo. São Paulo: Atlas, 1990.

TSCHOHL, John. Encantando totalmente o cliente. São Paulo: Makron Books, 1996.

WATSON, Rod. Comparative Sociology, Laic and Analytic: Some Critical Remarks on Comparison in Conversation Analysis. In: Cahiers de Praxématique, 50, 2008, p. 197-239. Disponível em: http://praxematique.revues.org/967. Acesso em: 28 nov. 2017.

WEBSTER JR., F. E. The changing role of marketing in the corporation. Journal of Marketing, Vol. 56, No. 4, p. 1-17, 1992. 


\section{Cynthia Maciel Duarte}

É doutora em Comunicação Social pela PUC-Rio, onde desenvolveu a tese "Comunicação e etnometodologia na Feira de São Cristóvão: interação social e comércio na Loja do China”, realizada com apoio da CAPES/PDSE. É mestre em Comunicação Social pela UERJ com a dissertação “A Magia da Disney no Facebook: estratégias de comunicação e negócios do conglomerado na rede social", indicada para concorrer ao prêmio Capes de teses e dissertações. É especialista em Mídia, tecnologia e educação pela PUC-Rio e graduada em Relações Públicas e Jornalismo pela UERJ. Tem mais de 10 anos de experiência em comunicação corporativa.

\section{Jacira Matos de Oliveira}

É mestre em Cultura Contemporânea e Novas Tecnologias pela Universidade Nova de Lisboa/Portugal, especialista em Gestão Estratégica de Negócios e graduada em Publicidade e Propaganda pela PUC-Minas. Há 15 anos trabalha lado a lado de empresas que desejam se destacar e consolidar a sua imagem, a sua reputação, e aumentar as suas vendas. Fundou a Saiba Planejar com o propósito de elaborar estratégias que ajudarão as Pequenas e Médias Empresas (PMEs) a conquistarem resultados mais efetivos para seus negócios por meio de ações de Marketing Digital. Atua como CMO na empresa Onni Clube de Benefícios e Vantagens.

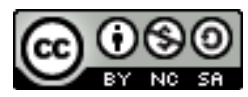

Esta obra está licenciada com uma Licença Creative Commons Atribuição-NãoComercial-CompartilhaIgual 4.0 Internacional 